\title{
Outcomes after craniotomy for resection of craniopharyngiomas in adults: analysis of the National Surgical Quality Improvement Program (NSQIP)
}

\author{
Andrew K. Rock ${ }^{1,2}$ - Alper Dincer ${ }^{1}$ - Matthew T. Carr ${ }^{1} \cdot$ Charles F. Opalak $^{1} \cdot$ Kathryn G. Workman $^{1}$. \\ William C. Broaddus ${ }^{1,2}$
}

Received: 25 April 2019 / Revised: 2 June 2019 / Accepted: 4 June 2019 / Published online: 21 June 2019

(c) Springer Science+Business Media, LLC, part of Springer Nature 2019

\begin{abstract}
Purpose Craniopharyngiomas occur in suprasellar locations that pose challenges for surgical management. This study evaluates the incidence of complications following craniotomy for craniopharyngioma in adults and investigates risk factors for these complications.

Methods Patients who underwent craniotomy for excision of craniopharyngioma were identified from the 2005-2016 American College of Surgeons National Surgical Quality Improvement Program (ACS-NSQIP). Incidence of 30-day postoperative complications was determined. Multivariable logistic regression identified demographic, comorbid and perioperative characteristics associated with any complication and major (Clavien IV) complications.

Results There were 143 cases identified. Fifty-one (35.7\%) had a complication, twenty (14.0\%) experienced a major complication and there were four (2.8\%) deaths. The most common complications were: unplanned readmission (13.3\%), prolonged ventilation $>48 \mathrm{~h}(9.8 \%)$, and unplanned reoperation (9.3\%). In multivariable analysis, variables significantly associated with any complication were: black race (OR 0.16; 95\% CI 0.03-0.84; $\mathrm{p}=0.03$ ), hypertension (OR 5.04; 95\% CI 1.79-14.17; $\mathrm{p}=0.002$ ) and longer duration of surgery (OR 1.27; 95\% CI 1.01-1.58; $\mathrm{p}=0.04$ ). Hypertension (OR 9.33; 95\% CI 1.61-54.21; $\mathrm{p}=0.01$ ) and longer duration of surgery (OR 1.51;95\% CI 1.05-2.17; $\mathrm{p}=0.03$ ) were also significant predictors for major complications. Conclusion One-third of patients undergoing craniotomy for craniopharyngioma resection experienced a postoperative complication. While high, this contrasts previously reported rates of two-thirds. Prolonged operative time and hypertension are positive predictors of major complications. This information can assist in counseling patients and decision-making for management. We note that other treatment approaches, such as endoscopic surgical techniques, radiosurgery and radiation therapy likely have different profiles and predictors of complications.
\end{abstract}

Keywords NSQIP · Craniotomy $\cdot$ Postoperative complications $\cdot$ Craniopharyngioma $\cdot$ Risk stratification $\cdot$ Outcome

\section{Introduction}

Craniopharyngiomas are epithelial tumors that occur in the sellar, parasellar, and suprasellar regions. They comprise $3 \%$ of all intracranial tumors and demonstrate a bimodal age

William C. Broaddus

william.broaddus@vcuhealth.org

1 Department of Neurosurgery, Virginia Commonwealth University, 417 North 11 th Street, Sixth Floor, P.O. Box 980631, Richmond, VA 23219-0631, USA

2 Department of Physiology and Biophysics, Virginia Commonwealth University, 1101 East Marshall Street, P.O. Box 980551, Richmond, VA 23298-0551, USA distribution peaking in childhood (5-14 years of age) and adulthood (50-74 years of age) [1]. Although considered a benign tumor, craniopharyngiomas are associated with considerable morbidity and mortality, often by impinging adjacent structures including: the sella turcica, hypothalamus, optic nerves and third ventricle [2]. Craniopharyngiomas have the highest overall mortality of all suprasellar tumors, with standardized mortality ratios ranging from $2.88-9.28$ when compared to the general population in cohort studies [3-5]. Long-term morbidity of these tumors can involve hypopituitarism, increased cardiovascular mortality, reduced quality of life and impaired cognitive function [6]. With maximal surgical resection, overall survival rates are reported as $95 \%$ at 2 years, $91 \%$ at 5 years, and $83-90 \%$ at 10 years $[7,8]$. 
Surgical resection has remained the first-line therapy for craniopharyngiomas, and complete resection has had the best reported outcomes in terms of overall and recurrencefree survival [7, 9]. Complete resection of the tumor, however, is often not possible because critical neurovascular structures limit the extent of resection.

To date, there has been no in-depth analysis of the incidence of morbidity and mortality or the risk factors for postoperative complications related to craniotomy for craniopharyngioma resection using a national database. Validating the safety of craniotomy for craniopharyngioma within a multiinstitutional national database will better inform clinicians and patients. The current study utilizes the American College of Surgeons National Surgical Quality Improvement Program (ACS-NSQIP) to investigate this topic and create a generalizable baseline for complication incidence and risk factors predictive of these complications. Because the ACS-NSQIP was designed to capture safety data for adult patients only, we have taken advantage of the availability of this large multicenter database to characterize the safety profile of craniotomies for craniopharyngioma in the adult patient population.

\section{Methods}

\section{Data source}

Data were obtained from the 2005-2016 ACS-NSQIP database. Details on the sampling strategy, data abstraction procedure, variables, outcomes, and structure of the ACSNSQIP have been published elsewhere [10-13]. In 2016, there were 680 participating sites, which collected approximately 274 standardized variables related to indexed surgical cases. Variables of interest include: patient demographics, preoperative risk factors, laboratory values, and postoperative complications derived from clinical data. Personnel at each participating site were trained to collect this data using standardized definitions. Each patient with an indexed surgical case was followed for 30 days to determine the presence of postoperative complications. Data audits were regularly performed to ensure data reliability.

\section{Inclusion and exclusion criteria}

Patients were included if they met the following criteria: (1) current procedural terminology (CPT) code indicating craniotomy for excision of craniopharyngioma (61545); and

(2) case performed by a neurosurgeon.

\section{Exposure variables}

Demographic characteristics included age, sex, race (white, black, other), body mass index (BMI) and tobacco use. BMI was classified according to the World Health Organization's definitions [14]. Clinical characteristics included preoperative comorbidities (diabetes, dyspnea, hypertension, disseminated cancer, chronic steroid use), American Society of Anesthesiologists (ASA) Physical Status classification (I-II, III, IV-V), transfer status (admitted directly from home, other), and duration of surgery in hours. Preoperative laboratory values included: serum sodium, white blood cell (WBC) count, hematocrit and platelet count.

\section{Outcomes}

The clinical outcomes of interest included dichotomized (yes/no) 30-day postoperative complications. The term "any complication" was used to denote the presence of at least one postoperative complication. The Clavien classification system for surgical complications was used to further categorize major postoperative complications [15]. Clavien class IV complications included any single or multi-organ dysfunction that would require intermediate care or intensive care unit (ICU) management [16, 17]. Clavien IV complications have been previously defined in the ACS-NSQIP as postoperative septic shock, dialysis, pulmonary embolism (PE), myocardial infarction (MI), prolonged ventilator status $>48 \mathrm{~h}$, or unplanned intubation $[18,19]$. Prolonged hospital stay was considered any length of stay (LOS) $>30$ days. Reasons for unplanned reoperation and readmission were determined based on the International Classification of Diseases Clinical Modification (ICD-9-CM, ICD-10-CM) system. Several postoperative complications may reflect presence of preexisting conditions at the time of surgery rather than new onset complications. If patients presented with a pre-existing condition preoperatively, they were considered ineligible for developing the associated postoperative complications.

\section{Statistical analysis}

Descriptive statistics were obtained. The incidence of 30-day postoperative complications was determined. Multivariable logistic regression models were used to investigate the relationship between the exposure variables and postoperative complications. Outcomes of interest for these models included any complication and major (Clavien IV) complications. Mortality was not assessed as an outcome in multivariable models due to its rarity. The area under the receiver operating characteristics curve (AUC) was calculated for each model to assess its predictive ability. All statistical analyses were performed using Stata (version 12.1, Stata Corp LP, College Station, Texas, USA). P values were set to a significance level of 0.05 . Data were analyzed in accordance with the data user agreement of the American College of Surgeons. This study was exempt from Institutional 
Table 1 Descriptive statistics for study sample

\begin{tabular}{|c|c|c|c|c|}
\hline Variable & Total $(\mathrm{n}=143, \%)$ & $\begin{array}{l}\text { Any complication } \\
(\mathrm{n}=51, \%)\end{array}$ & $\begin{array}{l}\text { No complication } \\
(\mathrm{n}=92, \%)\end{array}$ & $P$ value \\
\hline \multicolumn{5}{|l|}{ Age } \\
\hline$<35$ & $24(16.8)$ & $8(15.7)$ & $16(17.4)$ & \multirow[t]{5}{*}{0.62} \\
\hline 35 to $<45$ & $33(23.1)$ & $10(19.6)$ & $23(25.0)$ & \\
\hline 45 to $<55$ & $24(16.8)$ & $8(15.7)$ & $16(17.4)$ & \\
\hline 55 to $<65$ & $33(23.1)$ & $11(21.6)$ & $22(23.9)$ & \\
\hline$>65$ & $29(20.3)$ & $14(27.5)$ & $15(16.3)$ & \\
\hline \multicolumn{5}{|l|}{ Sex } \\
\hline Female & $72(52.4)$ & $27(52.9)$ & $45(48.9)$ & 0.64 \\
\hline \multicolumn{5}{|l|}{ Race } \\
\hline White & $101(70.6)$ & $37(72.6)$ & $64(69.6)$ & \multirow[t]{3}{*}{0.30} \\
\hline Black & $19(13.3)$ & $4(7.8)$ & $15(16.3)$ & \\
\hline Other & $23(16.1)$ & $10(19.6)$ & $13(14.1)$ & \\
\hline \multicolumn{5}{|l|}{ Body mass index } \\
\hline Under/normal Weight & $28(19.6)$ & $9(17.7)$ & $19(20.7)$ & \multirow[t]{4}{*}{0.06} \\
\hline Overweight & $43(30.1)$ & $9(17.7)$ & $34(37.0)$ & \\
\hline Obese class I & $40(28.0)$ & $18(35.3)$ & $22(23.9)$ & \\
\hline Obese class II-III & $32(22.4)$ & $15(29.4)$ & $17(18.5)$ & \\
\hline Tobacco use & $32(22.4)$ & $9(17.7)$ & $23(25.0)$ & 0.31 \\
\hline Diabetes & $28(19.6)$ & $13(25.5)$ & $15(16.3)$ & 0.19 \\
\hline Dyspnea & $9(6.3)$ & $3(5.9)$ & $6(6.5)$ & 0.88 \\
\hline Hypertension & $52(36.4)$ & $27(52.9)$ & $25(27.2)$ & 0.002 \\
\hline Disseminated cancer & $14(9.8)$ & $3(5.9)$ & $11(12.0)$ & 0.24 \\
\hline Chronic steroid use & $26(18.2)$ & $13(25.5)$ & $13(14.1)$ & 0.09 \\
\hline \multicolumn{5}{|l|}{ ASA classification } \\
\hline I-II & $41(28.7)$ & $10(19.6)$ & $21(33.7)$ & \multirow[t]{3}{*}{0.01} \\
\hline III & $83(58.0)$ & $29(56.9)$ & $54(58.7)$ & \\
\hline IV-V & $19(13.3)$ & $12(23.5)$ & $7(7.6)$ & \\
\hline \multicolumn{5}{|l|}{ Transfer status } \\
\hline Directly from home & $111(77.6)$ & $34(66.7)$ & $77(83.7)$ & \multirow[t]{2}{*}{0.02} \\
\hline Other & $32(22.4)$ & $17(33.3)$ & $15(16.3)$ & \\
\hline Duration of Surgery (hrs) & $4.55 \pm 2.37$ & $5.07 \pm 0.37$ & $4.28 \pm 0.23$ & 0.05 \\
\hline \multicolumn{5}{|l|}{ Sodium, mEq/L } \\
\hline$<137$ & $27(18.9)$ & $10(37.0)$ & $17(63.0)$ & \multirow[t]{3}{*}{0.87} \\
\hline $137-141$ & $88(61.5)$ & $30(34.1)$ & $58(65.9)$ & \\
\hline$>141$ & $28(19.6)$ & $11(39.3)$ & $17(60.7)$ & \\
\hline \multicolumn{5}{|l|}{ White blood cell count $/ \mu 1$} \\
\hline$<6000$ & $92(64.3)$ & $33(64.7)$ & $59(64.1)$ & \multirow[t]{3}{*}{0.89} \\
\hline 6000 to 12,000 & $25(17.5)$ & $8(15.7)$ & $17(18.5)$ & \\
\hline$>12,000$ & $26(18.2)$ & $10(19.6)$ & $16(17.4)$ & \\
\hline \multicolumn{5}{|l|}{ Hematocrit, \% } \\
\hline$<34.0$ & $19(13.3)$ & $28(54.9)$ & $61(66.3)$ & \multirow[t]{3}{*}{0.33} \\
\hline $34.0-39.0$ & $35(24.5)$ & $7(13.7)$ & $12(13.0)$ & \\
\hline$>39.0$ & $89(62.2)$ & $16(31.4)$ & $19(20.7)$ & \\
\hline \multicolumn{5}{|l|}{ Platelet Count $/ \mu \mathrm{l}$} \\
\hline$<200,000$ & $34(23.8)$ & $26(51.0)$ & $45(48.9)$ & \multirow[t]{3}{*}{0.97} \\
\hline $200,000-300,000$ & $71(49.7)$ & $12(23.5)$ & $22(23.9)$ & \\
\hline$>300,000$ & $38(26.6)$ & $13(25.5)$ & $25(27.2)$ & \\
\hline
\end{tabular}

Descriptive statistics for study sample for patients with and without any complication ASA American Society of Anesthesiologists 
Review Board (IRB) approval as only de-identified data were received and analyzed.

\section{Results}

\section{Demographics of study population}

In this study, a retrospective review of 5,209,692 surgical cases during years 2005 to 2016 was conducted using the ACS-NSQIP participant data use files (PUFs). Cases with missing data were excluded from this study $(n=8)$. A total of 143 patients were identified who underwent craniotomy for craniopharyngioma resection between years 2005 and 2016. Demographics, comorbidities, clinical characteristics, and preoperative laboratory values are presented in Table 1 . The mean age was $50.4 \pm 16.6$ years with a range from 18 to 89 years. Over half of the sample was female $(52.4 \%)$ and $13.3 \%$ were black race. Common comorbidities included: hypertension $(36.4 \%)$, tobacco use $(22.4 \%)$, diabetes (19.6\%), and chronic steroid use (18.2\%).

\section{Outcomes}

Of the 143 patients, there were $51(35.7 \%)$ cases with a complication and 20 (14.0\%) cases with a major complication. Figure 1 presents the incidence of complications and Table 2 contains the most common complications and their mean days to occurrence. Unplanned readmission $(13.3 \%)$ at a mean of 15.3 days, prolonged ventilation $>48 \mathrm{~h}(9.8 \%)$ with an average time on ventilator of 4.2 days, unplanned reoperation $(9.3 \%)$ at a mean of 13.0 days, deep vein thrombosis $(7.0 \%)$ at an average of 11.8 days, and cerebrovascular accident/stroke $(6.3 \%)$ at a mean of 6.1 days were the most frequent complications. Prolonged LOS greater than 30 days occurred in $11(7.7 \%)$ patients.

Reasons for unplanned reoperation and readmission are provided in Table 3. Postoperative hydrocephalus requiring unplanned reoperation occurred in 4 (2.7\%) patients. Unplanned readmission for electrolyte or fluid balance issues occurred in $6(4.2 \%)$ patients. The 30 -day mortality rate was $2.8 \%$ with mean occurrence at 13.0 days.



Fig. 1 Incidence of postoperative complications following craniopharyngioma resection. Incidence of postoperative complications following craniopharyngioma resection. SSI surgical site infection, CVA cerebrovascular accident 
Table 2 Incidence and timing of 30-day postoperative complications following craniotomy for craniopharyngioma resection

\begin{tabular}{lcl}
\hline Complication & Frequency $(\%)$ & Mean days from surgery \\
\hline Any complication & $51(35.7)$ & \\
Any morbidity & $51(35.7)$ & - \\
Superficial SSI & $2(1.4)$ & $16.50 \pm 4.95$ \\
Deep SSI & $1(0.7)$ & 24.00 \\
Organ space SSI & $1(0.7)$ & 29.00 \\
Wound dehiscence & $0(0.0)$ & - \\
Urinary tract infection & $8(5.6)$ & $13.86 \pm 6.96$ \\
Sepsis & $5(3.5)$ & $13.40 \pm 9.18$ \\
Pneumonia & $4(2.8)$ & $13.00 \pm 10.39$ \\
Deep vein thrombosis & $10(7.0)$ & $11.80 \pm 5.81$ \\
Myocardial infarction & $1(0.7)$ & - \\
Renal insufficiency & $0(0.0)$ & - \\
CVA/Stroke & $9(6.3)$ & $6.11 \pm 4.91$ \\
Transfusion within $72 \mathrm{~h}$ & $7(4.9)$ & $0.29 \pm 0.49$ \\
Unplanned reoperation & $13(9.1)$ & $13.00 \pm 5.48$ \\
Unplanned readmission & $19(13.3)$ & $15.25 \pm 7.57$ \\
Major (Clavien IV) complication & $20(14.0)$ & - \\
Septic shock & $1(0.7)$ & 10.00 \\
Cardiac arrest & $1(0.7)$ & 14.00 \\
Pulmonary embolism & $7(4.9)$ & $4.21 \pm 4.61$ \\
Acute renal failure & $0(0.0)$ & - \\
Prolonged ventilation $>48 \mathrm{~h}$ & $14(9.8)$ & $4.21 \pm 4.62$ \\
Unplanned reintubation & $9(6.3)$ & $6.11 \pm 5.64$ \\
Mortality & $4(2.8)$ & $13.00 \pm 5.48$ \\
Prolonged hospital stay $>30$ days & $11(7.7)$ & - \\
\hline & & \\
\hline & &
\end{tabular}

Incidence and timing of 30-day postoperative complications following craniotomy for craniopharyngioma resection

SSI surgical site infection, $C V A$ cerebrovascular accident

\section{Multivariable analysis}

Multivariable logistic regression modeling was used to evaluate the relationship between the exposure variables and postoperative complications (Table 4). Independent predictors for any complication were: black race (OR 0.16; 95\% CI $0.03-0.84 ; \mathrm{p}=0.03$ ), hypertension (OR 5.04; 95\% CI $1.79-14.17 ; \mathrm{p}=0.002)$, and longer duration of surgery (OR 1.27; 95\% CI 1.01-1.58; $\mathrm{p}=0.04$ ). The only independent risk factors for major complications were a history of hypertension (OR 9.33; 95\% CI 1.61-54.21; $\mathrm{p}=0.01$ ) and longer duration of surgery (OR 1.51; 95\% CI 1.05-2.17; $\mathrm{p}=0.03$ ). All other exposure variables did not have significant associations with postoperative complications. The AUC values from fully adjusted multivariable models for any complication and major complications were 0.82 and 0.90 , respectively.

\section{Discussion}

Evidence-based guidelines do not currently exist for the management of craniopharyngiomas in adults, and prospective randomized clinical trials comparing surgical approaches would require multicenter collaboration and many years due to the rarity of these tumors. This study is the first to utilize the American College of Surgeons National Surgical Quality Improvement Program (ACSNSQIP) to achieve a large multi-center sample and assess the risk factors and complications associated with the transcranial approach for resection of craniopharyngiomas in adults.

Out of 143 patients, $36 \%$ had any complication and $14 \%$ had a major complication. This is a markedly lower overall complication rate than reported in previous single center retrospective studies that ranged from 66 to $79 \%$ [20, 21]. The incidence of CVA/stroke in our study was $6.3 \%$, which is consistent with the range of 2.9 to $8.3 \%$ reported in previous studies [20,22]. Readmission due to hydrocephalus occurred in $2.7 \%$, which is lower than the rate of $10 \%$ (20 out of 198 ) 
Table 3 Reasons for unplanned reoperation and readmission within 30-days of craniopharyngioma resection

\begin{tabular}{|c|c|c|}
\hline ICD-9-CM/ICD-10-CM code & Description & Frequency $(\%)$ \\
\hline \multicolumn{3}{|l|}{ Unplanned reoperation } \\
\hline 331.3 & Communicating hydrocephalus & $1(0.08)$ \\
\hline 331.4 & Obstructive hydrocephalus & $2(0.15)$ \\
\hline 415.19 & Other pulmonary embolism and infarction & $1(0.08)$ \\
\hline 518.81 & Acute respiratory failure & $1(0.08)$ \\
\hline 998.12 & Hematoma complicating a procedure & $1(0.08)$ \\
\hline 998.32 & Disruption of external operation (surgical) wound & $1(0.08)$ \\
\hline G91.9 & Hydrocephalus, unspecified & $1(0.08)$ \\
\hline G93.89 & Other specified disorders of brain & $1(0.08)$ \\
\hline G97.82 & Other postprocedural complications and disorders of nervous system & $1(0.08)$ \\
\hline Unknown & - & $3(0.23)$ \\
\hline \multicolumn{3}{|l|}{ Unplanned readmission } \\
\hline 253 & Disorders of the pituitary gland and its hypothalamic control & $1(0.05)$ \\
\hline 253.5 & Diabetes insipidus & $1(0.05)$ \\
\hline 276.1 or E87.1 & Hypo-osmolality and/or hyponatremia & $3(0.15)$ \\
\hline 276.51 & Dehydration & $1(0.05)$ \\
\hline 322.9 & Meningitis, unspecified & $1(0.05)$ \\
\hline 348.9 & Unspecified condition of brain & $1(0.05)$ \\
\hline 780 & General symptoms & $1(0.05)$ \\
\hline 780.6 & Fever and other physiologic disturbances of temperature regulation & $1(0.05)$ \\
\hline 785 & Symptoms involving cardiovascular system & $2(0.10)$ \\
\hline $\mathrm{E} 87.8$ & Other disorders of electrolyte and fluid balance, not elsewhere classified & $1(0.05)$ \\
\hline $\mathrm{R} 11.2$ & Nausea with vomiting, unspecified & $1(0.05)$ \\
\hline Unknown & - & $5(0.26)$ \\
\hline
\end{tabular}

Reasons for unplanned reoperation and readmission within 30-days of craniopharyngioma resection

ICD-9-CM/ICD-10-CM international classification of diseases clinical modification

reported in a meta-analysis of 5 studies by Komotar et al. [21, 22]. The increased incidence in the meta-analysis could reflect longer duration of follow-up for complications and inclusion of hydrocephalus unrelated to readmission in the studies. The mortality rate in our study was $2.8 \%$, which is consistent with rates of $3 \%$ reported in other studies [20, 22]. The inconsistencies with previous studies might be due to historical changes in peri-operative management or different durations of followup. However, given the large and multicenter nature of this dataset, this is likely an externally valid incidence.

Within the constraints of the available data, a high incidence of postoperative complications (35.7\%) was observed that was significantly associated with history of hypertension, longer duration of surgery and non-black race. History of hypertension was a strong predictor for any (OR 5.04; 95\% CI 1.79-14.17; $\mathrm{p}=0.002$ ) and major complications (OR 9.33; 95\% CI 1.61-54.21; p=0.01). Within the ACS-NSQIP, this variable is defined as high blood pressure $(>140 / 90 \mathrm{mmHg}$ ) requiring anti-hypertensive medication for at least two weeks within the 30 days prior to surgery. Further investigation will be necessary to clarify this association.
Longer duration of surgery was significantly associated with any complication (OR 1.27; 95\% CI 1.01-1.58; $\mathrm{p}=0.04$ ) and major complications (OR 1.51;95\% CI $1.05-2.17 ; \mathrm{p}=0.03)$. This may reflect intraoperative factors related to the individual tumor's anatomical complexity. In cases of longer duration, however, surgeons should have an even higher index of suspicion for possible postoperative complications.

Black race had significantly lower likelihood of any complication (OR 0.16; 95\% CI 0.03-0.84; p=0.03). An explanation for this observed relationship remains elusive. Within the Surveillance, Epidemiology and End Results (SEER) Program, black race had 1.26 (95\% CI 0.98-1.59) times higher age-adjusted incidence of craniopharyngiomas when compared to white race with substantially reduced 1-year (87.4\% vs. $92.2 \%)$ and 3-year $(74.8 \%$ vs. $89.9 \%)$ relative survival rates. Our study demonstrated lower odds of 30-day postoperative complications in those who were black when compared to those who were white. These findings suggest that the previous findings of reduced overall prognosis in 
Table 4 Multivariable logistic regression modeling for exposure variables and postoperative complications

\begin{tabular}{|c|c|c|c|c|c|c|c|}
\hline \multirow[t]{2}{*}{ Variable } & \multirow{2}{*}{$\begin{array}{l}\text { Overall sample } \\
(\mathrm{n}=143, \%)\end{array}$} & \multicolumn{3}{|c|}{ Any complication $(\mathrm{n}=51)$} & \multicolumn{3}{|c|}{ Major complications $(n=20)$} \\
\hline & & $\%$ & OR $(95 \% \mathrm{CI})$ & $P$ value & $\%$ & OR $(95 \% \mathrm{CI})$ & $P$ value \\
\hline \multicolumn{8}{|l|}{ Age } \\
\hline$<35$ & $24(16.8)$ & 15.7 & 1.00 (Reference) & - & 12.5 & 1.00 (Reference) & - \\
\hline 35 to $<45$ & $33(23.1)$ & 19.6 & $1.12(0.24-5.37)$ & 0.88 & 9.1 & $0.21(0.01-3.24)$ & 0.26 \\
\hline 45 to $<55$ & $24(16.8)$ & 15.7 & $0.97(0.18-5.32)$ & 0.98 & 29.2 & $2.66(0.24-29.97)$ & 0.43 \\
\hline 55 to $<65$ & $33(23.1)$ & 21.6 & $0.82(0.16-4.31)$ & 0.82 & 9.1 & $0.54(0.04-7.33)$ & 0.64 \\
\hline$>65$ & $29(20.3)$ & 27.5 & $2.32(0.39-13.88)$ & 0.36 & 13.8 & $1.49(0.11-19.62)$ & 0.76 \\
\hline \multicolumn{8}{|l|}{ Sex } \\
\hline Female & $72(52.4)$ & 52.9 & $1.96(0.72-5.29)$ & 0.19 & 15.3 & $1.53(0.34-6.78)$ & 0.58 \\
\hline \multicolumn{8}{|l|}{ Race } \\
\hline White & $101(70.6)$ & 72.6 & 1.00 (Reference) & - & 14.9 & 1.00 (Reference) & - \\
\hline Black & $19(13.3)$ & 7.8 & $0.16(0.03-0.84)$ & 0.03 & 10.5 & $0.39(0.05-3.05)$ & 0.37 \\
\hline Other & $23(16.1)$ & 19.6 & $1.08(0.30-3.82)$ & 0.91 & 13.0 & $0.70(0.07-6.85)$ & 0.76 \\
\hline \multicolumn{8}{|l|}{ Body mass index } \\
\hline Under/normal weight & 28 (19.6) & 17.7 & 1.00 (Reference) & - & 10.7 & 1.00 (Reference) & - \\
\hline Overweight & $43(30.1)$ & 17.7 & $0.46(0.11-1.93)$ & 0.29 & 7.0 & $1.85(0.14-24.88)$ & 0.64 \\
\hline Obese class I & $40(28.0)$ & 35.3 & $1.90(0.48-7.45)$ & 0.36 & 10.0 & $1.42(0.10-20.26)$ & 0.80 \\
\hline Obese class II-III & $32(22.4)$ & 29.4 & $1.21(0.28-5.26)$ & 0.80 & 31.3 & $13.02(0.76-223.26)$ & 0.08 \\
\hline Tobacco use & $32(22.4)$ & 17.7 & $0.59(0.17-1.99)$ & 0.40 & 12.5 & $0.62(0.08-4.64)$ & 0.64 \\
\hline Diabetes & 28 (19.6) & 25.5 & $1.04(0.28-3.94)$ & 0.95 & 28.6 & $4.98(0.70-35.61)$ & 0.11 \\
\hline Dyspnea & $9(6.3)$ & 5.9 & $0.44(0.08-2.57)$ & 0.36 & 11.1 & $0.51(0.03-7.62)$ & 0.62 \\
\hline Hypertension & $52(36.4)$ & 52.9 & $5.04(1.79-14.17)$ & 0.002 & 25.0 & $9.33(1.61-54.21)$ & 0.01 \\
\hline Disseminated cancer & $14(9.8)$ & 5.9 & $0.32(0.04-2.36)$ & 0.26 & 7.1 & $0.39(0.01-17.88)$ & 0.63 \\
\hline Chronic steroid use & $26(18.2)$ & 25.5 & $2.87(0.85-9.68)$ & 0.09 & 19.2 & $0.55(0.09-3.52)$ & 0.53 \\
\hline \multicolumn{8}{|l|}{ ASA classification } \\
\hline I-II & $41(28.7)$ & 19.6 & 1.00 (Reference) & - & 9.8 & 1.00 (Reference) & - \\
\hline III & $83(58.0)$ & 56.9 & $0.87(0.27-2.82)$ & 0.81 & 13.3 & $0.34(0.04-2.73)$ & 0.31 \\
\hline IV-V & $19(13.3)$ & 23.5 & $3.67(0.69-19.68)$ & 0.13 & 26.3 & $2.42(0.20-30.03$ & 0.49 \\
\hline \multicolumn{8}{|l|}{ Transfer status } \\
\hline Directly from home & 111 (77.6) & 66.7 & 1.00 (Reference) & - & 10.8 & 1.00 (Reference) & - \\
\hline Other & $32(22.4)$ & 33.3 & $1.88(0.64-5.54)$ & 0.25 & 25.0 & $1.73(0.32-9.45)$ & 0.29 \\
\hline Duration of Surgery (hrs) & $4.55 \pm 2.37$ & - & $1.27(1.01-1.58)$ & 0.04 & - & $1.51(1.05-2.17)$ & 0.03 \\
\hline \multicolumn{8}{|l|}{ Sodium, mEq/L } \\
\hline$<137$ & $27(18.9)$ & 37.0 & $1.58(0.46-5.40)$ & 0.46 & 14.8 & $3.15(0.37-26.56)$ & 0.29 \\
\hline $137-141$ & $88(61.5)$ & 34.1 & 1.00 (Reference) & - & 12.5 & 1.00 (Reference) & - \\
\hline$>141$ & 28 (19.6) & 39.3 & $1.21(0.35-4.18)$ & 0.77 & 17.9 & $6.39(0.86-47.60)$ & 0.07 \\
\hline \multicolumn{8}{|l|}{ White blood cell count $/ \mu 1$} \\
\hline$<6000$ & $92(64.3)$ & 64.7 & 1.00 (Reference) & - & 15.2 & 1.00 (Reference) & - \\
\hline 6000 to 12,000 & $25(17.5)$ & 15.7 & $0.59(0.17-2.02)$ & 0.41 & 4.0 & $3.15(0.37-26.56)$ & 0.48 \\
\hline$>12,000$ & $26(18.2)$ & 19.6 & $1.00(0.27-3.75)$ & 1.00 & 19.2 & $2.02(0.27-14.94)$ & 0.49 \\
\hline \multicolumn{8}{|l|}{ Hematocrit, \% } \\
\hline$<34.0$ & $19(13.3)$ & 54.9 & $0.83(0.16-4.34)$ & 0.83 & 15.8 & $0.49(0.03-9.23)$ & 0.63 \\
\hline $34.0-39.0$ & $35(24.5)$ & 13.7 & $1.55(0.50-4.75)$ & 0.45 & 11.4 & $0.19(0.02-1.57)$ & 0.12 \\
\hline$>39.0$ & $89(62.2)$ & 31.4 & 1.00 (Reference) & - & 14.6 & 1.00 (Reference) & - \\
\hline \multicolumn{8}{|l|}{ Platelet count $/ \mu 1$} \\
\hline$<200,000$ & $34(23.8)$ & 51 & $1.68(0.50-5.60)$ & 0.40 & 14.7 & $0.91(0.12-6.95)$ & 0.92 \\
\hline $200,000-300,000$ & 71 (49.7) & 23.5 & 1.00 (Reference) & - & 16.9 & 1.00 (Reference) & - \\
\hline$>300,000$ & 38 (26.6) & 25.5 & $1.07(0.35-3.24)$ & 0.90 & 7.9 & $0.52(0.09-3.02)$ & 0.47 \\
\hline AUC & - & - & 0.82 & & - & 0.90 & \\
\hline
\end{tabular}

Results from multivariable logistic regression modeling evaluating the relationship between the exposure variables and postoperative complications

OR odds ratio, CI confidence interval, ASA American Society of Anesthesiologists 
this population may be related to longer-term survival factors unrelated to the immediate postoperative period.

The findings of this study need to be interpreted in light of its limitations. The ACS-NSQIP is nationally based, but still has the potential for selection bias related to the nonrandomized participation of certain institutions over others. Outcomes are limited to the initial 30-day postoperative period and do not factor in longer-term consequences of surgery, which may reduce the apparent incidence of postoperative complications observed. Additionally, the postoperative complications in the ACS-NSQIP were not comprehensive, also potentially leading to an underestimate. In particular, postoperative changes in visual or endocrine function were not recorded for the ACS-NSQIP. The robust sample size allowed for investigation into risk factors for any and major complications but remained insufficient to evaluate predictors for rarer outcomes like mortality. While endoscopic strategies for treating craniopharyngiomas have gained in popularity and frequency, the ACS-NSQIP does not, as yet, have adequate numbers of these procedures to characterize the profile and predictors of complications for endoscopic surgical approaches, which may be different from those of open cranial approaches. Likewise, treatment strategies utilizing radiosurgery and radiotherapy are not represented in the database, thus could not be analyzed for comparison. Despite these limitations, the ACS-NSQIP offers informative data on standardized 30-day postoperative complications for a larger sample of patients with craniopharyngiomas than can be found at a single institution.

\section{Conclusion}

Craniotomy for craniopharyngioma resection in adults is associated with a $35.7 \%$ incidence of 30-day postoperative complications, including: unplanned readmission, prolonged ventilation $>48 \mathrm{~h}$, and unplanned reoperation. Unplanned readmission was frequently related to electrolyte disturbances and hypopituitarism that are characteristic of suprasellar lesions. These findings, along with the risk factors (history of hypertension, longer duration of surgery) observed in this study could be used to establish management changes in an effort to reduce postoperative complications following craniotomy for craniopharyngioma resection. This is the first study to examine the incidence of complications following craniotomy for resection of craniopharyngioma. Given the large and multicenter nature of the dataset it is expected to have high external validity. It can better inform surgeons when counseling their patients on the possible risks of craniotomy for resection of craniopharyngioma and allow for future comparisons between craniotomy and other surgical approaches for craniopharyngioma management as a step to further reduce complications. The information provided by this study regarding risk factors for major complications of craniotomy for craniopharyngiomas can contribute to the surgeon's ability to counsel patients and families regarding management choices, which also must take into account considerations of outcomes not addressed by the ACS-NSQIP, such as likelihood of complete resection, long-term survival and the implications of potential permanent neurologic complications.

Funding AR received funding for this study from the Virginia Commonwealth University Year Out Master's Program. AD and MC received funding for this study from the Virginia Commonwealth University Dean's Summer Research Fellowship. The authors report no external funding source for this study.

\section{Compliance with ethical standards}

Conflict of interest: The authors declare no conflict of interest.

\section{References}

1. Jane JA Jr, Laws ER (2006) Craniopharyngioma. Pituitary 9(4):323-326. https://doi.org/10.1007/s11102006-0413-8

2. Zoicas F, Schofl C (2012) Craniopharyngioma in adults. Front Endocrinol (Lausanne) 3:46. https://doi.org/10.3389/fendo .2012 .00046

3. Bulow B, Attewell R, Hagmar L, Malmstrom P, Nordstrom CH, Erfurth EM (1998) Postoperative prognosis in craniopharyngioma with respect to cardiovascular mortality, survival, and tumor recurrence. J Clin Endocrinol Metab 83(11):3897-3904. https:// doi.org/10.1210/jcem.83.11.5240

4. Pereira AM, Schmid EM, Schutte PJ et al (2005) High prevalence of long-term cardiovascular, neurological and psychosocial morbidity after treatment for craniopharyngioma. Clin Endocrinol (Oxf) 62(2):197-204

5. Tomlinson JW, Holden N, Hills RK et al (2001) Association between premature mortality and hypopituitarism. West midlands prospective hypopituitary study group. Lancet 357(9254):425-431

6. Erfurth EM, Holmer H, Fjalldal SB (2013) Mortality and morbidity in adult craniopharyngioma. Pituitary 16(1):46-55. https://doi. org/10.1007/s11102-012-0428-2

7. Van Effenterre R, Boch AL (2002) Craniopharyngioma in adults and children: a study of 122 surgical cases. J Neurosurg 97(1):311. https://doi.org/10.3171/jns.2002.97.1.0003

8. Karavitaki N, Brufani C, Warner JT et al (2005) Craniopharyngiomas in children and adults: systematic analysis of 121 cases with long-term follow-up. Clin Endocrinol (Oxf) 62(4):397-409

9. Turel MK, Tsermoulas G, Gonen L et al (2016) Management and outcome of recurrent adult craniopharyngiomas: an analysis of 42 cases with long-term follow-up. Neurosurg Focus 41(6):E11. https://doi.org/10.3171/2016.9.FOCUS16315

10. Mortini P, Losa M, Pozzobon G et al (2011) Neurosurgical treatment of craniopharyngioma in adults and children: early and longterm results in a large case series. J Neurosurg 114(5):1350-1359. https://doi.org/10.3171/2010.11.JNS10670

11. Khuri SF, Daley J, Henderson W et al (1998) The department of veterans affairs' NSQIP: The first national, validated, outcome-based, risk-adjusted, and peer-controlled program for the 
measurement and enhancement of the quality of surgical care. National VA surgical quality improvement program. Ann Surg 228(4):491-507

12. Khuri SF, Henderson WG, Daley J et al (2007) The patient safety in surgery study: background, study design, and patient populations. J Am Coll Surg 204(6):1089-1102

13. Khuri SF, Henderson WG, Daley J et al (2008) Successful implementation of the department of veterans affairs' national surgical quality improvement program in the private sectOR The patient safety in surgery study. Ann Surg 248(2):329-336. https://doi. org/10.1097/SLA.0b013e3181823485

14. WHO (1995) Physical status: the use and interpretation of anthropometry. report of a WHO expert committee. World Health Organ Tech Rep Ser 854:1-452

15. Clavien PA, Barkun J, de Oliveira ML et al (2009) The claviendindo classification of surgical complications: five-year experience. Ann Surg 250(2):187-196. https://doi.org/10.1097/ SLA.0b013e3181b13ca2

16. Clavien PA, Sanabria JR, Strasberg SM (1992) Proposed classification of complications of surgery with examples of utility in cholecystectomy. Surgery 111(5):518-526

17. Dindo D, Demartines N, Clavien PA (2004) Classification of surgical complications: a new proposal with evaluation in a cohort of 6336 patients and results of a survey. Ann Surg 240(2):205-213

18. Obeid NM, Azuh O, Reddy S et al (2012) Predictors of critical care-related complications in colectomy patients using the national surgical quality improvement program: exploring frailty and aggressive laparoscopic approaches. J Trauma Acute Care
Surg 72(4):878-883. https://doi.org/10.1097/TA.0b013e3182 $4 \mathrm{~d} 0 \mathrm{f} 70$

19. Webb S, Rubinfeld I, Velanovich V, Horst HM, Reickert C (2012) Using national surgical quality improvement program (NSQIP) data for risk adjustment to compare clavien 4 and 5 complications in open and laparoscopic colectomy. Surg Endosc 26(3):732-737. https://doi.org/10.1007/s00464-011-1944-2

20. Jeswani S, Nuno M, Wu A et al (2016) Comparative analysis of outcomes following craniotomy and expanded endoscopic endonasal transsphenoidal resection of craniopharyngioma and related tumors: a single-institution study. J Neurosurg 124(3):627-638. https://doi.org/10.3171/2015.3.JNS142254

21. Wannemuehler TJ, Rubel KE, Hendricks BK et al (2016) Outcomes in transcranial microsurgery versus extended endoscopic endonasal approach for primary resection of adult craniopharyngiomas. Neurosurg Focus 41(6):E6. https://doi. org/10.3171/2016.9.FOCUS16314

22. Komotar RJ, Starke RM, Raper DM, Anand VK, Schwartz TH (2012) Endoscopic endonasal compared with microscopic transsphenoidal and open transcranial resection of craniopharyngiomas. World Neurosurg 77(2):329-341

Publisher's Note Publisher's Note Springer Nature remains neutral with regard to jurisdictional claims in published maps and institutional affiliations. 